\title{
Ethical Dilemmas Associated With Profit-Driven Research in Developing Countries
}

\author{
EVANGEL SARWAR, Ph.D., MPH \\ evangel.sarwar@gmail.com
}

\begin{abstract}
The phenomenal growth of the global pharmaceutical sales, which exceeded \$US one trillion in revenues in 2014 alone, has resulted in the growing ethical concerns associated with the need for the unprecedented search for human test subjects to participate in clinical drug trials - particularly in middle and low-income countries - and concerns about possible exploitation. While this expansion has provided access to vital medical resources that would have otherwise been unattainable for this population - this outsourcing also created problems which may be termed as exploitation - such as faulty trials at times, and manipulation of data about the benefits and risks of the drugs being tested on the populations in developing countries. Although the United States and European countries have sponsored much biomedical research in developing countries, they considered their work done once the trials concluded, and this has been criticized and termed as "safari research," - which is a form of exploitation of developing countries and their populations from which research subjects are recruited. These trials do not address the needs of the developing countries and contribute to the exploitation of some of the most "vulnerable" populations. It is unethical to enter a country, set up facilities for research then leave with the healthcare personnel and equipment after giving hope to its people of some form of benefit. Several historical events have led to the awareness of the need for protecting research subjects. There is a need for a better understanding of what constitutes as exploitations, to ensure researchers make ethical decisions with planning and implementation of research involving research participants. The paper looks at the ethical issues and their importance in international research, and the double standards that are of growing concern in profit-driven research in low-income countries by developed sponsor countries, while also making recommendations for preventing exploitations.
\end{abstract}

\section{INTRODUCTION}

Medical enterprise has grown enormously, resulting in the need to expand outside of the United States by investing in medical research in developing countries. While this expansion into low-income countries has provided opportunities for the populations, this outsourcing also created new problems involving faulty trials at times, utilization of biased tools that manipulate data about the benefits and risks of the drugs being tested on the vulnerable populations in developing countries - some of them resulting in exploitation. ${ }^{1}$ This paper looks at the ethical issues associated with exploitation, and double standards in profit-driven research in low-income countries by developed sponsor countries. The focus of this paper is on: exploitation of research participants - research not addressing the needs of the developing country, and vulnerability of the people due to poverty and lack of healthcare; double standards - standard of care used in research for participants, and obligations of researchers, and sponsors to provide the successful products of research to the populations of the country participating; and recommended solutions.

*Address correspondence to: Evangel Sarwar. Ph.D., E-mail: evangel.sarwar@gmail.com

+To cite this article: Evangel Sarwar "The Ethics of Food and Childhood Obesity - A Public Health Issue," The Journal of Healthcare Ethics \& Administration 5, no. 1 (Fall/Winter 2019)22-35, https://doi.org/10.22461/jhea.1.71621

This work is brought to you for free and open access by the Institute of Clinical Bioethics (ICB) at Saint Joseph's University, Philadelphia, PA, U.S.A. It has been accepted for inclusion in The Journal of Healthcare Ethics \& Administration by the editorial board and an authorized administrator of the JHEA. For more information, please contact support@jheaonline.org

\footnotetext{
${ }^{1}$ Adriana Petryana, When experiments travel: Clinical trials and the global search for human subjects, (Princeton and Oxford: Princeton University Press, 2009), 1.
} 


\section{THE JOURNAL OF HEALTHCARE ETHICS \& ADMINISTRATION}

Vol. 5 | No. 1 (Fall/Winter 2019)

\section{EXPLOITATION OF RESEARCH PARTICIPANTS}

The phenomenal growth of global pharmaceutical sales has resulted in an unprecedented search for human test subjects to participate in clinical drug trials, particularly in middle and low-income countries. While it has been noted that these experiments are probably the only way, vital unattainable medical resources are obtained by those who lack these, the outsourcing and offshoring of trials also create new problems. Several events concerning exploitation and abuse of human subjects in history have led to society becoming increasingly aware and sensitive to the ethical concerns; development of ethical standards and guidelines; need to ensure the possibility of exploitation and harm is minimized; that research participants are not a means to an end but treated with respect. ${ }^{2}$ Before ethics was a concern, research conducted was up to the discretion of the researcher, where some researchers experimented on themselves and died; while in the academia, they only had to secure support and cooperation of peers and superiors in their departments. ${ }^{3}$ Proper conduct in research involving humans has faced considerable dilemmas. ${ }^{4}$ Avoiding exploitation is the fundamental ethical challenge of all research. ${ }^{5}$ Ethical codes of conducts have been developed to guide researchers in avoiding exploitation of vulnerable populations in underdeveloped societies. ${ }^{6}$ Better understanding of what constitutes as exploitation and what does not, helps researchers make ethical decisions with planning and implementing research. This section looks at the ethical issues in international research and why they are important, by focusing on the concerns raised due to research not addressing the needs of the developing countries; and exploitation of "vulnerable" participants, due to poverty and lack of access to healthcare.

\section{A. Research not Addressing the Needs of Developing Country}

Despite longstanding and widespread knowledge of the devastating toll diseases continue to take on populations in developing countries, industrialized nations have largely avoided playing an active role in seeking to improve the health status of people particularly in developing countries. ${ }^{7}$ Research on the effectiveness and safety of disease treatment, diagnosis, and prevention has increased; however, diseases which are most prevalent in those developing countries remain neglected - their control requires local research yet traditions of scientific research and infrastructure for it are limited. ${ }^{8}$ There should be a relevance of research to the needs of research participants as well as their communities and nations. At present many emerging and developing countries have limited capacity to determine national health and research priorities, or to conduct relevant research, leading to their dependence on the external sponsor's interests. The accompanying benefits of sponsoring research to individual researchers, their institutions, and even policymakers, such as improved healthcare facilities, and other benefits to the individual researchers, may be motivational and manipulative in preventing developing countries from research that is unlikely to benefit to the population. ${ }^{9}$

There is an obligation to help developing countries build their own capacity to conduct research independently. Elements of capacity-building include training scientists and other research personnel; contributing to the research and healthcare infrastructure in the community or country; and most recently, providing training for scientific and ethical review of research. It is true that the United States and European countries have sponsored many biomedical researches in developing countries. However, once the trials

\footnotetext{
2 Paul Ndbele, "Research Ethics," in The SAGE Handbook of Healthcare Ethics: Core and Emerging Issues, ed. Ruth Chadwick, Henk ten Have and Eric Meslin, (Los Angeles: SAGE, 2011), 306.

3 Paul Ndbele, "Research Ethics," 307.

${ }^{4}$ Paul Oliver, The student's guide to research ethics. (Maidenhead, UK: McGraw Hill/Open University Press, 2010$), 1$.

${ }^{5}$ Ezekiel J. Emanuel, David Wendler and Christine Grady, "An Ethical Framework for Biomedical Research" in The Oxford Textbook of Clinical Research Ethics, ed. Ezekiel J. Emanuel, Christine Grady, Robert A. Crouch, Reidar K. Lie, Franklin G. Miller and David Wendler, (Oxford/New York: Oxford University Press, 2008), 125.

${ }^{6}$ Alan Wertheimer, "Exploitation in Clinical Research" in The Oxford Textbook of Clinical Research Ethics, ed. Ezekiel J. Emanuel, Christine Grady, Robert A. Crouch, Reidar K. Lie, Franklin G. Miller and David Wendler, (Oxford/New York: Oxford University Press, 2008$), 201$.

${ }^{7}$ Ruth Macklin, Double standards in medical research in developing countries. (Cambridge UK: Cambridge University Press, 2004$), 12$.

8 Juhana E. Idanpaan-Heikkila and Sev S. Fluss, "Exploitation in Clinical Research" in The Oxford Textbook of Clinical Research Ethics, ed. Ezekiel J. Emanuel, Christine Grady, Robert A. Crouch, Reidar K. Lie, Franklin G. Miller and David Wendler, (Oxford/New York: Oxford University Press, 2008), 168

9 Paul Ndbele, "Research Ethics," 315.
} 


\section{THE JOURNAL OF HEALTHCARE ETHICS \& ADMINISTRATION}

Vol. 5 | No. 1 (Fall/Winter 2019)

concluded - the sponsors considered their work done. This has been criticized and termed as "safari research," which comes close to being a form of exploitation of poor countries and their populations from which research subjects are recruited. It is unethical to enter a country, set up facilities for research, then leave with the healthcare personnel and equipment. ${ }^{10}$ As beneficial as capacity building is for poor countries, it is far from sufficient as a means of alleviating the conditions of historically prevalent diseases such as malaria and tuberculosis, and HIV/AIDS. Data from both the Centers for Disease Control and Prevention (CDC) and the World Health Organization (WHO) reported 940,000 deaths from AIDS-related illnesses in 2017 with Sub-Saharan Africa, accounting for 66\% for all new HIV infections worldwide. ${ }^{11,12,13,14,15}$ Yet, antiretroviral therapy (ART) which is reasonably effective in prolonging the lives of HIV-infected people in most industrialized countries, has been available only to a tiny minority of wealthy individuals in developing countries. $^{16}$

Today, private funding holds supremacy over public investments in clinical research; and the neoliberal model applied to the health field has induced a decline in state power, both concerning establishing national priorities in research and influencing the development of adequate ethical guidelines for this kind of research. The international pharmaceutical industry is one of the branches of economic activity with the largest concentration of capital. Worldwide pharmaceutical revenues exceeded \$US one trillion in 2014, with branded patented medicines constituting the largest share of revenues according to data - and research and development play a significant role in revenue generation. ${ }^{17}$ A captive market and a monopoly of patents have been crucial factors in causing these enormous earnings on the part of the industry. ${ }^{18}$ Although it has been noted that approximately 50,000 international clinical trials were being conducted, more than $40 \%$ took place in poor and low-income countries. It is disturbing that only a small number of the investigation by multinational companies are aimed at meeting the needs of the poorer countries in which the research is being conducted. It has also been noted that poor and low-income countries have been increasingly involved in multicenter clinical trials aimed at expanding the fields of testing and market in the last decade. However, it is not enough. ${ }^{19}$

The discrepancy between the increasing participation of poor and low-income countries in transnational clinical trials and the investments in drug trials targeting diseases that affect mainly patients in the sponsoring countries is evident in several recent studies. Findings from a study demonstrate that approximately one-third of the trials (157 of 509) were conducted outside the USA, mostly in poor low-income countries, and none of these trials were directed towards diseases that preferentially affect the countries involved. ${ }^{20}$ Studies also found that out of the 1556 new drugs developed worldwide between 1975 and 2004 , only ten drugs were for predominantly prevalent diseases in low-income countries. When malaria and tuberculosis are included, this number of new drugs rises to 21 . This indicates that only $1 \%$ of pharmacological innovations during the past 30 years, in which the involvement of developing countries in multicenter clinical trials was the greatest, were directed at diseases that predominantly affect the populations of those countries. It was also found that none of the ongoing phase 3 clinical trials sponsored by US-based companies, were for diseases such as tuberculosis that disproportionately affect the populations of these countries. ${ }^{21}$

Another factor that could increase this discrepancy is the imposition of TRIPS-Plus provisions to poor and low-income countries, something that could significantly reduce the capacity of these countries to provide adequate public access to medicines and jeopardize the development of autonomous biomedical industry production. ${ }^{22}$ This discrepancy between prevalent health needs

\footnotetext{
${ }^{10}$ Ruth Macklin, Double standards in medical research in developing countries, 12.

${ }^{11}$ Ruth Macklin, Double standards in medical research in developing countries, 13.

12 "Global HIV \& AIDS statistics - 2018 fact sheet,"World Health Organization.

${ }^{13}$ Centers for Disease Control and Prevention (CDC). "HIV Surveillance Report: Diagnoses of HIV Infection in the United States and Dependent Areas," vol 29 (2017).

14 "Fact sheets: overweight and obesity: key facts." World Health Organization, (2019)

15 The Kaiser Family Foundation. "The Global HIV/AIDS Epidemic." (2019)

${ }^{16}$ Volnei Garrafa et al. "Between the needy and the greedy: the quest for a just and fair ethics of clinical research. Journal of Medical Ethics, no. 36 (2010): 500 .

${ }^{17}$ Volnei Garrafa et al. "Between the needy and the greedy: the quest for a just and fair ethics of clinical research." 501.

${ }^{18}$ Claudio Lorenzo, Volnei Garrafa, Jan Helge Solbakk, and Susana Videl, "Hidden risks associated with clinical trials in developing countries", Journal of Medical Ethics, no. 36(2010): 111.

${ }^{19}$ Claudio Lorenzo et al. "Hidden risks associated with clinical trials in developing countries", 112.

${ }^{20}$ Leonardo D. de Castro, Peter A. Sy and Teoh Chin Leong. "Poverty and Indigenous Peoples", in The SAGE Handbook of Healthcare Ethics: Core and Emerging Issues, ed. Ruth Chadwick, Henk ten Have and Eric Meslin, (Los Angeles: SAGE, 2011), 294.

${ }^{21}$ Ekopimo Ibial, et.al. "Ethical considerations in industry sponsored Multiregional Clinical Trials," Pharmaceutical Statistics, no. 9(2010): 233.

22 Leonardo D. de castro, Peter A. Sy and Teoh Chin Leong. "Poverty and Indigenous Peoples", in The SAGE Handbook of Healthcare Ethics: Core and Emerging Issues, 292.
} 


\section{THE JOURNAL OF HEALTHCARE ETHICS \& ADMINISTRATION}

Vol. 5 | No. 1 (Fall/Winter 2019)

and research priorities have been labeled as the 10/90 gap. This was introduced to depict the monstrous inequity in the world with respect to whose diseases were favored in ongoing or planned research programs. $90 \%$ of the economic resources spent annually on medical research targets the health needs of the richest $10 \%$ of the world's population. This implies that the needs of the $90 \%$ have to be met from the remaining $10 \%$ of the research funding. This gap exists, and the number of people from poor and low-income countries has increased substantially. The relative availability of new drugs to populations in poor and low-income countries has not increased, the gap between wealthy and developing nations about who benefits from advances in clinical research continues to widen.

\section{B. "Vulnerable" Due to Poverty and Lack of Access to Healthcare}

Public concerns are being expressed globally regarding whether Western countries undertaking or sponsoring research in developing countries may be exploiting underserved populations for cost advantages and profits, and/or testing drugs in local populations, the outcomes of which would benefit patients mostly in Western countries. Poverty, low literacy, relative lack of understanding of research and its procedures, and possible undue inducements may contribute to the enhanced vulnerability of patient populations, especially those who may not have access to basic healthcare. ${ }^{23}$ As Ruth Macklin rightly points out, "the needs of the disadvantaged or vulnerable populations deserve particular attention," and similar rights, and level of protection as those granted to research participants from Western countries. ${ }^{24} \mathrm{~A}$ matter of growing concern is the increasing number of studies that drug companies conduct in developing countries because the research can be done there more quickly and with less oversight, thereby enabling the companies to gain approval for marketing and realize a profit as soon as possible. ${ }^{25}$ Exploitation violates justice as fairness because, in one way or another, people having greater power or resources take unfair advantage of those with less power or fewer resources. People can also be exploited based on their ignorance, weaknesses, or lack of sophistication. ${ }^{26}$

Concerns have arisen about the possibility that vulnerable people might be exposed to unacceptable risks and potential harms in developing countries that lack insufficient protections for human subject research. Companies from industrial countries research in resource-poor countries, where the diseases targeted are not as prevalent, or a high priority as others in the host country raises ethical questions about exploitation. Typically, developed countries sponsor/conduct research in developing countries for these four reasons: upon host country's desire for information about effective and affordable interventions for an indigenous health problem; drugs need to be tested and approved by national regulatory authorities prior to marketing; efficient to conduct research where conditions studied is prevalent; and less expensive and faster to conduct research in emerging and developing countries. Use of incentives act as agents in developing countries to recruit participants, causes for concerns related to vulnerability due to poverty; not being well informed about human subjects research, and informed consent not being a well-established requirement in the practice of clinical medicine or research in those countries. ${ }^{27}$

Known problems of offshoring are the 'availability' of patients facing medical crisis and poverty, unequal terms of trials that draw heavily from public resources, whose immediate benefits only reach a few. Due to the number of trials run, a large number of subjects are required. ${ }^{28}$ Need for large subject cohorts, to satisfy U.S. regulatory demands regarding long term safety of a new drug, means that trials must include a greater number of patients. The bigger the population, the faster the drugs regulatory approval will be. Regulatory considerations and calculations of cost-effectiveness continue to play a crucial role and are pushing the research enterprise to other shores. ${ }^{29}$ Participants from poor countries, such as Eastern Europe and Eurasia are apt to be accommodating they are receiving Western medical treatments they could not otherwise pay for, and they adhere to trial procedures and do what is asked of them. Physicians in those areas are competent, but poorly paid, they gravitate toward the money research brings. They are willing to become study monitors, provide support for other physician-investigators, and make sure that research protocols are properly executed. This task pays more than what a physician makes in those countries. ${ }^{30}$ Different kinds of patients have different

\footnotetext{
${ }^{23}$ Ruth Macklin, Double standards in medical research in developing countries, 5-6.

${ }^{24}$ Ruth Macklin, Ethics in Global Health: Research, Policy and Practice. (Oxford University Press, New York, 2012 ), 212.

25 Ruth Macklin, Double standards in medical research in developing countries. 122.

${ }^{26}$ Adriana Petryana, When experiments travel: Clinical trials and the global search for human subjects, 20.

${ }^{27}$ Adriana Petryana, When experiments travel: Clinical trials and the global search for human subjects, 31.

${ }^{28}$ Adriana Petryana, When experiments travel: Clinical trials and the global search for human subjects, 4.

${ }^{29}$ Adriana Petryana, When experiments travel: Clinical trials and the global search for human subjects, 3.

${ }^{30}$ Claudio Lorenzo et al. "Hidden risks associated with clinical trials in developing countries," 113.
} 


\section{THE JOURNAL OF HEALTHCARE ETHICS \& ADMINISTRATION}

Vol. 5 | No. 1 (Fall/Winter 2019)

stakes in clinical trials, as clinical trials become a form of mainstream medicine, the desperately ill might accept clinical trials as their best medical option rather than as 'mere' experimentation. For many taking part from poor countries that lack access to healthcare is access to better medical monitoring than what is usually provided in industrialized medicine. For those who lack health insurance, it is the only way to needed treatment. ${ }^{31}$

Social vulnerability focuses on the lifestyle structure of individuals and communities and relates to factors such as: lack of income, information, knowledge and technology; lack of access to political power and other types of social representation; a highly restricted network of social contacts; diversity of beliefs and customs with respect to the majority and extreme age and physical deficiencies. In poor and low-income countries, public health institutions have serious difficulties in providing adequate healthcare, something that creates obstacles with regard to the recruitment, training and support of specialized healthcare professionals. ${ }^{32,33}$ The Council for International Organizations of Medical Sciences (CIOMS) commentary Guideline 13 says that "a vulnerable person are those who are incapable of protecting their interests, due to insufficient power, intelligence, education, resources, strength or other needed attributes" (CIOMS 2002). In the context of research, an impaired ability to give voluntary, informed consent renders a potential subject vulnerable; being in a coercive environment such as prison or another institutional setting compromises freedom to decline such participation in research. ${ }^{34}$ Populations of developed countries are less likely to be exploited than are populations in developing countries, so the resulting situation is an inequitable selection of research subjects across international boundaries. The CIOMS acknowledges this situation in a commentary in Guideline 8: Research involving human subjects in underdeveloped communities, noting that "individuals and families in such communities are liable to exploitation for various reasons." ${ }^{5}$

It is expected that the expansion of clinical research and development activities to many countries and regions of the world with limited biomedical research experience and resources may lead to beneficial outcomes; including the diffusion of knowledge, transfer of technology, contribution to the improvement of health infrastructures, greater patient access to quality medical care, and indirectly to economic growth. ${ }^{36}$ Although such research endeavors present real opportunities, they are also filled with uncertainties and challenges. International clinical research may occur across regions/countries where thriving economies may coexist with widespread poverty and increasing social gaps; basic healthcare, adequate infrastructures, and health insurance may not be widely available to all of the population. As Paul Ndbele notes, the research-based industry is also confronted with regulatory, clinical, operational/logistical, statistical, and ethical challenges "due to the inherent variability in culture, medical practice, laws and regulations, level of understanding of clinical research itself and its process, and inadequate independent, properly constituted, and well-trained ethics committees." Clinical studies should be performed only in countries where there is a reasonable expectation that the drug tested will be submitted for marketing authorization and made available once proven safe. There is growing ethical concern related to the ever-increasing involvement of populations of poor and low-income countries in clinical research originating from affluent countries, mainly related to the possibility of a double standard of care related to the use of placebo in clinical trials and lack of post-trial availability of interventions. ${ }^{37}$ Most of the times the population and governments are too poor to be able to afford the drugs developed from the results of these trials. The next section looks at double standards and issues of justice, where the benefits are not equally distributed.

\section{DOUBLE STANDARDS}

Recently, a lot of concerns have been expressed about the exploitation of research participants from poor countries - partly fueled by fears of medical-ethical imperialism, and partly fueled by fears about the use of double standards. ${ }^{38}$ Maged El Setouhy and colleagues state that clinical research conducted by sponsors and researchers from developed countries have grown controversial,

\footnotetext{
${ }^{31}$ Ruth Macklin, Ethics in Global Health: Research, Policy and Practice. (Oxford University Press, New York, 2012 ), 149.

32 Ruth Macklin, Ethics in Global Health: Research, Policy and Practice, 164.

${ }^{33}$ Ruth Macklin, Ethics in Global Health: Research, Policy and Practice, 212.

${ }^{34}$ Ekopimo Ibial et.al. "Ethical considerations in industry sponsored Multiregional Clinical Trials," 231

${ }^{35}$ Claudio Lorenzo et al. "Hidden risks associated with clinical trials in developing countries," 111.

${ }^{36}$ Paul Ndbele, "Research Ethics," 314-315.

37 Maged El Setouhy et al. "Moral Standards for Research in Developing Countries from "Reasonable Availability" to "Fair Benefits." The Hastings Center Report, Vol. 34, No. 3(2004), 17.

${ }^{38}$ Maged El Setouhy et al. "Moral Standards for Research in Developing Countries from "Reasonable Availability" to "Fair Benefits," 18
} 


\section{THE JOURNAL OF HEALTHCARE ETHICS \& ADMINISTRATION}

Vol. 5 | No. 1 (Fall/Winter 2019)

and they cite the perinatal HIV transmission studies, as an example that was sponsored by the National Institutes of Health (NIH) and the CDC, conducted in Southeast Asia and Africa. Ethical questions were raised about placebo trials and whether the treatments tested in developing countries were acceptable and should be compared to the treatments provided locally or elsewhere; and whether drugs that were proven effective in the trial are required to be made available to the host population after the trial ended? ${ }^{39}$ The standards provided by Ethical Guidelines issued in 1993 by the ClOMS about the necessity for "reasonable availability" to avoid exploitation seems to have been under disagreement by the pharmaceutical companies, leading to the revision of the Declaration of Helsinki. ${ }^{40}$ This recent revision has fueled concerns of double standards of "standards of care" in poor countries.

\section{A. Ethical Standards, "Standard of Care" and Lack of Access to Post-Trial Care}

Ethical concerns regarding monetary research compensation and continued provision of care after trial completion are raised due to the existence of the disparity in bargaining powers that exist between populations and researchers in emerging countries, and the principle of social justice. The perceived benefits could create an incentive strong enough for those research participants who have little or no access to healthcare and could represent unintended undue influence. Although the ethics of financial incentives in clinical research has been discussed, no consensus has emerged on when, and in what manner it is ethical to pay research participants who are patients. Research sponsors are ethically committed, regardless of the country where the study is conducted; reimbursement for expenses should be reasonable, and in compliance with local laws, and regulations. Trial discussions and posttrial arrangements need to consider the seriousness of the studied condition, the local needs and infrastructures, and the availability (or lack) of effective treatments. According to the Declaration of Helsinki, patients entered into the study are entitled to a share of any benefits that result from it, or to other appropriate care or benefits. ${ }^{41}$ Provision of care and access to treatment post-trial are important ethical considerations, especially in resource-poor countries. Any plans and arrangements made, or agreements reached for the continuation of treatment, or other benefits, beyond the study should be discussed and properly documented before conducting the study.

According to the central tenet of distributive justice, it is not fair that populations in resource-poor countries suffer the potential burdens of research without the prospect of deriving benefits when research demonstrates that the experimental drug is safe and effective. The situation in which research subjects still require a successful product that they received during their participation in the study should not be made worse off after a clinical trial is over than they were while the research was being carried out. ${ }^{42}$ The conclusion of clinical trial triggers a new set of ethical obligations to research participants. ${ }^{43}$ Issues such as continuity of treatment and ongoing control of data sponsors pose specific medical challenges - patients require treatment that is now on the market and out of their reach, and trial sponsors still try to maintain control over patient data in drug-marketing phase. ${ }^{44}$ There are also escalating demands imposed by patients and marketers on doctors to prescribe, and to the state to provide new highcost medicines, some of whose clinical benefits are not unequivocally established. The ethical justification for the obligation to

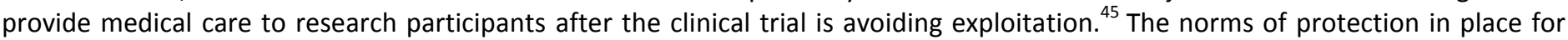
research participants in the U.S and internationally are modified and varies from place to place; data are strategically manufactured, and at times, strategically withheld. The benefits of research are arguably uncertain, and the risks are unevenly distributed, and its costs are unjust. ${ }^{46}$

It is now recognized that the benefits of research should be made available to the participants and communities that bear the burden of that research. Without the principle of distributive justice, participants could be exploited for research while its

\footnotetext{
${ }^{39}$ Ekopimo Ibial et al. "Ethical considerations in industry sponsored Multiregional Clinical Trials," 236.

40 James V. Lavery. "Exploitation in Clinical Research" in The Oxford Textbook of Clinical Research Ethics, ed. Ezekiel J. Emanuel, Christine Grady, Robert A. Crouch, Reidar K. Lie, Franklin G. Miller and David Wendler, (Oxford/New York: Oxford University Press, 2008), $697-700$.

${ }^{41}$ Lavery, "Exploitation in Clinical Research" in The Oxford Textbook of Clinical Research Ethics, 698.

${ }^{42}$ Adriana Petryana, When experiments travel: Clinical trials and the global search for human subjects, 141.

${ }^{43}$ Ruth Macklin, Double standards in medical research in developing countries, 79-80

${ }^{44}$ Adriana Petryana, When experiments travel: Clinical trials and the global search for human subjects, 188.

45 Paul Ndbele, "Research Ethics," in The SAGE Handbook of Healthcare Ethics: Core and Emerging Issues, 318.

${ }^{46}$ M Botbol-Baum. "The shrinking of human rights: the controversial revision of the Helsinki Declaration," HIV Medicine, 2000 (1): 238.
} 


\section{THE JOURNAL OF HEALTHCARE ETHICS \& ADMINISTRATION}

Vol. 5 | No. 1 (Fall/Winter 2019)

benefits go wholly elsewhere. ${ }^{47}$ According to the Ethical Guidelines issued in 1993 by the Council for International Organizations of Medical Sciences (CIOMS), four issues have generated disagreement to the need for the requirement for making any successful product developed through such research to the participating population 'reasonably available': 1 . How strong/explicit should the commitment to provide the drug or vaccine be at the initiation of the research trial (per CIOMS)? CIOMS lists the requirement of an exact, contract-like mechanism, that must be agreed to before the trial, and the responsibility of which must be assigned to the sponsors of the research. The Declaration of Helsinki's 2000 revision endorses "a less stringent guarantee that does not require the availability of interventions to be ensured in advance." 2. Determining who is responsible for ensuring reasonable availability - the sponsors or host country government or other international organization? 3. Should the drug be made free, subsidized, or at market prices? 4. Should the interventions be made reasonably available to only the participants, or the entire population?

Many papers have addressed the controversial issue of the double standard of care following from the use of placebo in clinical trials given the recent revision of the Declaration. Placebo-control trials have always placed economic goals above the individual subjects' welfare, a position contrary to the principles embodied in the Declaration. Research is not reduced in developing countries, but the Declaration is modified to include arguments to make the trials defensible. ${ }^{48}$ The permission to use placebo in clinical trials conducted in poor and low-income countries included in the Declaration, favoring the interests of science and the pharmaceutical market over the ethical imperatives of protecting the safety and wellbeing of individual humans undergoing research - are reasons for great concern. Unfortunately, the ethical commitment of the Declaration has been eroded several times since the Nuremberg Code. The main argument was - the rights and welfare of the subjects had to be protected in clinical research, to be ethically justifiable, and research must serve the purposes of healing. The right to access to healthcare for HIV patients (for example) in developing countries has been weakened by the 1999 revision of the Helsinki Declaration, and the recent revision reflects the tendency that research is not healthcare oriented for all, but profit-oriented. ${ }^{49}$

Pharmaceutical companies are slowly replacing the ethical imperative of the Declaration with the idea that people in the developing country accepts the risks associated with participation; cannot find affordable drugs/vaccines; want to be exploited for the benefits of people in developed countries who are sponsoring this. The core of the double standard argument labeled as 'the minimalist position,' allows the use of different standards for research protocols and participants in the first and third world, because it assumes that members from poor countries are not entitled to more or better care than they receive currently. ${ }^{50}$ There was intense discussion over the latest revision of the Declaration of Helsinki at the Congress in bioethics organized by the Latin American countries; where the Declaration of Cordoba was unanimously adopted, this Declaration advises countries and governments to reject the $6^{\text {th }}$ version of the Declaration of Helsinki and recommends the Universal Declaration instead on Bioethics, and Human Rights as an ethical frame of reference. ${ }^{51}$ The new version can seriously affect the safety, wellbeing and rights of persons who participate in clinical trials. It would indeed be unethical for a country to bear the risks of hosting clinical trials without reaping some form of benefits for its citizens.

\section{B. Lack of Access to Successful Products of Research}

Expansion of clinical research and development may lead to beneficial outcomes. However, such expansion also points to aspects of controversies in research in poor countries - which include their lack of access and affordability of the drugs. ${ }^{52}$ The globalization process has worsened the social problems of developing countries and their dependence on foreign capital. This new world order has also influenced the research capacity of these countries. Most countries have limited capacity to determine national health and research priorities. This results in their dependence on the interests of external sponsors; and lack of refusal to offers to research. In the importance of protecting the poor from undue inducements as a result of powerful incentives, some of the benefits may have to be converted into community benefits - such as supporting clinics and engaging in other community projects that promote good health. Poor countries need to ensure that they are benefiting from the research in which their citizens and communities participate.

\footnotetext{
47 M Botbol-Baum. “The shrinking of human rights: the controversial revision of the Helsinki Declaration." 239.

${ }^{48}$ Volnei Garrafa et al. "Between the needy and the greedy: the quest for a just and fair ethics of clinical research." 502.

${ }^{49}$ Volnei Garrafa et al. "Between the needy and the greedy: the quest for a just and fair ethics of clinical research, 503.

${ }^{50}$ Ekopimo Ibial et al. "Ethical considerations in industry sponsored Multiregional Clinical Trials," 231-232.

${ }^{51}$ Ezekiel J. Emanuel. "Exploitation in Clinical Research" in The Oxford Textbook of Clinical Research Ethics, ed. Ezekiel J. Emanuel, Christine Grady, Robert A. Crouch, Reidar K. Lie, Franklin G. Miller and David Wendler, (Oxford/New York: Oxford University Press, 2008), 719-720.

${ }^{52}$ Teck-Chuan Voo, Jacqueline Chin, and Alastair V. Campbell. “Multinational Research," The Hastings Center Bioethics Briefing Book, $107-108$.
} 


\section{THE JOURNAL OF HEALTHCARE ETHICS \& ADMINISTRATION}

Vol. 5 | No. 1 (Fall/Winter 2019)

Although biomedical research is a practice with the ultimate aim not just to increase knowledge but improve human health and wellbeing, it also poses a risk of exploitation in research that might benefit people beyond those enrolled in the research study. ${ }^{53}$ The fundamental ethical challenge is that people and communities that participate in research are assuming risks and burdens, whereas the benefits of the knowledge gained from research can be extended to many other people who have not assumed risks or burdens. To minimize or avoid the possibility of exploitation, those who assume the risks and burdens of research should be assured of receiving fair benefits from research. This notion is embedded in ethical requirements that biomedical research has social value. There are some serious discussions about how poor countries are being assured of access to drugs based on the trial-participations of their citizens. The focus on communities has also been a result of the importance that some cultures place on communities. Although the new or improved drugs resulting from this research may reach the market in developed countries relatively quickly; they may never be sold in developing host countries due to the inability of the countries to purchase them - as a result, research participants are not receiving a fair share of benefits. ${ }^{54} \mathrm{An}$ argument defending this is that the chief way of providing medical benefits to populations in resource-poor countries is to develop cheaper drugs - presumably affordable, but probably less effective than those considered to the "best current treatments" in industrialized countries. ${ }^{55}$

Post-trial obligations to ensure access to beneficial treatments for participants in clinical trials are widely viewed as a mechanism to avert exploitation - emphasizes the continued provision of beneficial drugs and devices. ${ }^{56}$ There are guidelines that talk about the post-trial benefits, the version 2002 CIOMS International Ethical Guidelines for Biomedical Research Involving Human Subjects (Guideline 10) states that the sponsor and the investigator must "ensure that the research is responsive to the health needs and priorities" of the host country before undertaking research initiatives, and that every effort should be taken to ensure that any intervention or product developed be made reasonably available for benefiting that population. ${ }^{57}$ The existing differentials in power, influence, and resources between host country communities and organizations and the foreign researchers and sponsors might confer an unfair bargaining advantage to the foreign investigators, and this might be manipulated to include inappropriate meaningful contributions to heal research participants. ${ }^{58}$ Deficiencies in "reasonable availability" standard of CIOMS guidelines layout a framework for ensuring this obligation. It makes the determination of appropriate benefits a matter of negotiation. The discussion on research benefits has also led to ancillary care debate. Proponents of access to healthcare have argued that research participants should be provided ancillary care - which is the care that is over and beyond the problem being investigated in a particular study. Debates have been held with funding agencies; some were arguing that ancillary care is the role of the government. However, ancillary care also provides a token of appreciation for the poor who volunteer as research participants. ${ }^{59}$

Several international guidelines recommend that externally sponsored research be reviewed by ethics committees or institutional review boards (IRBS) from both sponsor and host countries to make sure research participants are protected. However, this may not be easy for a developing country due to lack of capacity to conduct effective ethics review; or due to compromised IRB by the prospect of collaboration with powerful sponsors. To address the deficiencies the Office of Inspector General of the Department of Health and Human Services produced a report entitled: "The Globalization of Clinical Trials: A Growing Challenge in Protecting Human Subjects" (2001), recommending that the Food and Drug Administration investigates the performance of foreign IRBs and help them to develop capacity. It was also proposed that the DHHS Office for Human Research Protections encourage a voluntary accreditation system for foreign IRBs. ${ }^{60}$

The poverty status of the population often reveals the limits of local standards of care and the failure of states to protect citizens; resulting in the medical migration of patients and families from all over the country to participate - even from neighboring countries where treatment access are not available. ${ }^{61}$ For placebo trials, such as Gaucher treatment, to carry out placebo trials, the company commits to providing drugs to all patients for two or more years, but after that, the doctors have to deal with the aftermath, particularly continuity of treatment and quality of care as patients return home. There are no health infrastructures - no

\footnotetext{
53 Lavery. "Exploitation in Clinical Research" in The Oxford Textbook of Clinical Research Ethics, 697.

${ }^{54}$ Ruth Macklin, Double standards in medical research in developing countries, 163.

55 Lavery, "Exploitation in Clinical Research" in The Oxford Textbook of Clinical Research Ethics, 698-699.

56 Lavery, "Exploitation in Clinical Research" in The Oxford Textbook of Clinical Research Ethics, 701.

57 Paul Ndbele, "Research Ethics," 319-320.

58 Teck-Chuan Voo, Jacqueline Chin, and Alastair V. Campbell, "Multinational Research," 108.

${ }^{59}$ Adriana Petryana, When experiments travel: Clinical trials and the global search for human subjects, 168.

${ }^{60}$ Ezekiel J. Emanuel, David Wendler, Jack Killen, and Christine Grady. "What Makes Clinical Research in Developing Countries Ethical? The Benchmarks of Ethical Research," The Journal of Infectious Diseases, no 189(2004):930-7.

${ }^{61}$ Ezekiel J. Emanuel, David Wendler, Jack Killen, and Christine Grady. "What Makes Clinical Research in Developing Countries Ethical? The Benchmarks of Ethical Research," The Journal of Infectious Diseases. 930.
} 


\section{THE JOURNAL OF HEALTHCARE ETHICS \& ADMINISTRATION}

Vol. 5 | No. 1 (Fall/Winter 2019)

one is responsible for setting one up, some struggle for continued treatment, while others give up. As scholars like Ezekiel J. Emanuel and colleagues note, the conduct of the research should not undermine the community's existing healthcare services. It will be ethical to supplement the existing system through the provision of additional resources, equipment, medications, or training appropriate to the research to avoid exploitation. The scholars point out that the research study must be designed in such a way so that the results will be useful in the context of the health problem in the developing country. Moreover, they add that interventions should be selected to ensure that the design is useful in identifying effective or appropriate interventions; implementing socially, culturally, and economically appropriate changes in the healthcare system; or providing a reliable foundation for conducting subsequent research. The scholars also add that the study design must realize the research objectives while neither denying healthcare services that participants are otherwise entitled to, nor requiring services that are not feasible to deliver in the context of the country's healthcare system. Determining such entitlement to medical services in studies is challenging since they differ among countries. $^{62}$

Ekopimo Ibial et al. notes that the risk of exploitation of subjects or host communities in developed countries is minimized because researchers and research institutions are part of the larger community; with infrastructures that translates research results into healthcare practices for the benefit of the larger community. They also add that poverty, limited healthcare services, illiteracy, cultural and linguistic differences, and limited understanding of the nature of scientific research increase the possibility of exploitation. The regulatory infrastructures and independent oversight processes may be less well established, less supported financially, and less effective in developing countries. ${ }^{63}$ Guidelines for ethical research should reduce the risk of exploitation under these circumstances. Clinical studies should be performed only in countries with a reasonable expectation that the drugs will be available once proven safe. ${ }^{64}$ Pharmaceutical companies have a social and moral responsibility towards developing affordable drugs for poor countries. ${ }^{65}$

\section{PROPOSED SOLUTIONS}

Today, the majority of clinical research endeavors are industry sponsored. As pointed by Ruth Macklin, "clinical trials are studies designed to systematically evaluate new drugs or new ways of using known treatments in humans, before they enter the market." Macklin also emphasizes that "trials are imperfect and at times, biased instruments that may or may not yield the complete evidence about a drug's benefits and risks." ${ }^{66}$ To ensure that researchers are not conducting research for self-interested reasons; that people are not asked to volunteer where there are no benefits - there needs to be an oversight system in place. There must be rules formalized to strike the right balance between rigidity and flexibility so that valuable research is not hindered - at the same time - people are protected. ${ }^{67}$ Despite the Universal agreement that there must be some ethical standards that research involving humans must adhere by; there are surprising amounts of vagueness and disagreement in interpreting and applying this fundamental requirement. $^{68}$ U.S. Federal regulations require that research using federal funds conducted outside the United States must be reviewed by an IRB that has been approved by the U.S. Office of Human Research Protection (OHRP). ${ }^{69}$ The International guidelines have a set of guidelines for the ethical conduct of international research. Declaration of Helsinki: particularly concerned with the violations of human rights and medical ethics that took place in Germany and elsewhere during the Nazi period is arguably the most widely known and influential guideline in medical research worldwide - it introduces the concept of benefit in proportion to risk, stated that research was to be conducted only when necessary to promote the health of the population. ${ }^{70,71,72}$ Basic ethical

\footnotetext{
${ }^{62}$ Ekopimo Ibial et al. "Ethical considerations in industry sponsored Multiregional Clinical Trials,"232.

63 Adriana Petryana, When experiments travel: Clinical trials and the global search for human subjects, 1-3.

${ }^{64}$ Ruth Macklin, Ethics in Global Health: Research, Policy and Practice. 711.

${ }^{65}$ Ruth Macklin, “Exploitation in Clinical Research,” in The Oxford Textbook of Clinical Research Ethics, ed. Ezekiel J. Emanuel, Christine Grady, Robert A. Crouch, Reidar K. Lie, Franklin G. Miller and David Wendler, (Oxford/New York: Oxford University Press, 2008 ), $716-717$.

${ }^{66}$ Leonardo D. de castro, Peter A. Sy and Teoh Chin Leong. "Poverty and Indigenous Peoples", in The SAGE Handbook of Healthcare Ethics: Core and Emerging Issues, 293.

${ }^{67}$ Ruth Macklin, Double standards in medical research in developing countries, 5-6.

${ }^{68}$ Emanuel, "Exploitation in Clinical Research" in The Oxford Textbook of Clinical Research Ethics, 720.

${ }^{69}$ Ezekiel J. Emanuel et al. "What Makes Clinical Research in Developing Countries Ethical? The Benchmarks of Ethical Research," 932

${ }^{70}$ Ezekiel J. Emanuel et al. "What Makes Clinical Research in Developing Countries Ethical? The Benchmarks of Ethical Research," 933
} 


\section{THE JOURNAL OF HEALTHCARE ETHICS \& ADMINISTRATION}

Vol. 5 | No. 1 (Fall/Winter 2019)

principles of respect of persons, beneficence, and justice were identified in the Belmont Report, which was the result of the Tuskegee Study, apply to research to minimize risk and to make it ethical. ${ }^{73,74,75}$ Regulatory framework has arisen due to abuses carried out by researchers on vulnerable individuals; guidelines are in place today to avoid coercion, undue inducement, exploitation, and harm. ${ }^{76}$ The tenacity of controversies on such issues demonstrates that existing ethical guidelines can be interpreted in multiple ways, and can sometimes act as contradictory ethical principles. Although there are a lot of disagreements, the guidelines can be useful in conducting research that minimizes risks and avoids exploitation of participants. This section looks at what provisions can protect vulnerable subjects and looks at solutions.

\section{A. Make Provision to Protect Vulnerable Subjects}

Agomoni Ganguli-Mitra and Nikola Biller-Andorno states that a collaborative partnership between researchers and sponsors in developed countries and researchers, policymakers, and communities in developing countries will aid in reducing the possibility of exploitation by ensuring that the developing country determines for itself whether the research is acceptable and responsive to the community's health problems. ${ }^{77}$ Ezekiel and colleagues highlight the six benchmarks in collaborative partnership: First, it requires representatives from developing countries as partners. Second, the authors point that collaboration that entails "sharing responsibility for assessing the importance of the health problem and the value of the research to the community, for planning and conducting the study, disseminating the results, and ensuring that they are used for health improvements," are required. Third, demonstrable collaborative partnership that reflects mutual respect should exist. This reflects recognition of, and respect for the host community's unique values, culture, and social practices, which should be incorporated into the design and implementation of the study as noted by the authors. Fourth, a true collaborative partnership that aspires to minimize disparities related to research project between researchers and sponsors from developed countries and the host community should exist. This should take place through the development of healthcare research resources and investment in the healthcare sector. Fifth, the authors add that the community in which the research is being conducted should receive fair benefits from the conduct and/or results of the research; they note that such benefits might include employment and training for community members to augment healthcare services for the entire community. Sixth, the collaborative partnership should provide a fair distribution of the tangible and intangible rewards of research among the partners. The authors state that the unfair distribution of benefits of collaboration can only generate "more resentment, mistrust, and a sense of exploitation." Agreements on sharing intellectual property rights, royalties, and other sources of financial profit, as well as appropriate authorship and other credit for contributions to the research, may be required. ${ }^{78}$

This requirement has been the most influential attempt in ensuring that participants from developing countries benefit from participating. As noted by Ezekiel J. Emanuel, the CIOMS proposed this requirement in 1993, which after many revisions in 2002 was included in guideline10 which requires this as a means to avoid exploitation. Many, such as UNAIDS, have supported the reasonable availability requirement - any preventive vaccine such as HIV vaccines, demonstrated to be safe and effective as well as the knowledge and benefits resulting from the research of such vaccines must be available to the participant as soon as possible. The National Bioethics Advisory Commission (NBAC), in the United States, also states that if the intervention is not affordable in the developing countries then it is unethical to ask persons from those countries to participate. The NBAC concludes that researchers should consider how the participants might benefit before initiating research, and participants should be provided with the results of

\footnotetext{
${ }^{71}$ Richard E. Ashcroft. "The Declaration of Helsinki” in The Oxford Textbook of Clinical Research Ethics, ed. Ezekiel J. Emanuel, Christine Grady, Robert A. Crouch, Reidar K. Lie, Franklin G. Miller and David Wendler, (Oxford/New York: Oxford University Press, 2008$), 141$.

72 Richard E. Ashcroft. "The Declaration of Helsinki" in The Oxford Textbook of Clinical Research Ethics, 141-143.

73 Paul Ndbele. "Research Ethics," in The SAGE Handbook of Healthcare Ethics: Core and Emerging Issues, 307-308.

74 Paul Ndbele. "Research Ethics," in The SAGE Handbook of Healthcare Ethics: Core and Emerging Issues, 309.

${ }^{75}$ Ezekiel J. Emanuel and Christine Grady. "Four Paradigms of Clinical Research and Research Oversight" in The Oxford Textbook of Clinical Research Ethics, ed. Ezekiel J. Emanuel, Christine Grady, Robert A. Crouch, Reidar K. Lie, Franklin G. Miller and David Wendler, (Oxford/New York: Oxford University Press, 2008), 226.

${ }^{76}$ Tom L. Beauchamp. "Research Ethics," in The SAGE Handbook of Healthcare Ethics: Core and Emerging Issues, ed. Ruth Chadwick, Henk ten Have and Eric Meslin, (Los Angeles: SAGE, 2011), 149-150.

77 Agomoni Ganguli- Mitra and Nikola Biller-Andorno. "Vulnerability in healthcare and research ethics," in The SAGE Handbook of Healthcare Ethics: Core and Emerging Issues, ed. Ruth Chadwick, Henk ten Have and Eric Meslin, (Los Angeles: SAGE, 2011), 247.

${ }^{78}$ Emanuel. "Exploitation in Clinical Research" in The Oxford Textbook of Clinical Research Ethics, 721.
} 


\section{THE JOURNAL OF HEALTHCARE ETHICS \& ADMINISTRATION}

Vol. 5 | No. 1 (Fall/Winter 2019)

the intervention. ${ }^{79}$ According to the Boston University Bioethics, developed countries are exploiting the subjects in developing countries unless interventions are made available to them to quickly use the knowledge gained from these trials for their own benefits. Even Declaration of Helsinki has something similar - research is only justifiable if the population in which the research is carried out is benefitted from the results. ${ }^{80}$

According to James V. Lavery, the fair benefits model assumes that exploitation results from the unfair distribution of benefits within particular agreements. The author suggests making the results of the research available can be one way (although not the only way) to provide benefits to a population. ${ }^{81}$ Critics argue that the terms can be considered independent of the background economic conditions in low -and middle-income countries hosting the research, which are widely perceived to be unjust. ${ }^{82}$ Two fundamental assumptions are made: 1 . Key to avoiding exploitation is ensuring that people receive fair benefits. 2 . All the anticipated benefits from the research must be taken into consideration to determine the fair benefits. The population to receive benefits includes participants, as well as members of the community who might also bear burdens and risks for carrying on the research. This framework supplements the usual conditions for the ethical conduct of research. The fair benefits framework adds three additional principles for evaluating the ethics of individual research studies to ensure that participants get a fair share of benefits:

1. Fair Benefits: the conduct and result of the research should provide a comprehensive delineation of tangible benefits to the research participants and the population. Benefits must increase with the burdens; similarly, the benefits should also increase proportionally amongst the stakeholders and all those involved. ${ }^{83}$ 2.Collaborative partnership: the population being asked to enroll determines whether a particular array of benefits is sufficient and fair - with the host population determining the value of benefits for itself. Outsiders will likely not be well informed about health, the social and economic context in which the research is being conducted, and will not be in a position to fully appreciate the importance of the proposed benefits to the population. ${ }^{84} 3$. Transparency: is necessary to allow comparisons with similar transactions. A repository of all the benefits agreement should be established to permit an appropriate level of benefit to different countries.

\section{B. Striving for Universal Standards}

The protections that are in place in the U.S. is not the same elsewhere. ${ }^{85}$ The ethical requirements for human subjects' research rest on universal ethical principles even if those principles are not recognized or adhered to in all parts of the world. Just because certain ethical principles were first articulated in the West does not mean that such principles cannot be applied anywhere else. ${ }^{86}$ The wellknown and widely accepted ethical principles governing human subjects ought to be universal in application. Universality of principles should not be confused with the notion of "absolutist ethics." The universality refers to the scope of applicability of ethical principles, whereas absolutism implies an exceptionless set of moral rules or prescriptions. The principles are very general and require interpretation in light of relevant empirical facts and contexts before they can be applied. In contrast, "moral absolutes" are ethical judgments with specific content. Principles are necessary but not sufficient for a rich ethical analysis of human subjects' research among other human endeavors. There is a need to distinguish between procedural requirements of U.S. regulations and ethical principles that underlie them. These guidelines can be implemented in various ways in different countries. ${ }^{87}$

As Benjamin Caballero points out, ethical principles governing research with human subjects have evolved over the years from "the Nuremberg Code, the Declaration of Helsinki, and the Belmont Report." ${ }^{87}$ As enunciated in the Belmont Report, these principles are based on respect for persons (the principle that participation in research is voluntary and requires informed consent), beneficence (the principle that subjects must be protected from harm and that potential benefits must be balanced against the risks

\footnotetext{
79 Emanuel. "Exploitation in Clinical Research" in The Oxford Textbook of Clinical Research Ethics, 722.

${ }^{80}$ Emanuel, "Exploitation in Clinical Research" in The Oxford Textbook of Clinical Research Ethics, 725

81 Emanuel. "Exploitation in Clinical Research" in The Oxford Textbook of Clinical Research Ethics, 726.

${ }^{82}$ Ruth Macklin. Ethics in Global Health: Research, Policy and Practice. (Oxford University Press, New York, 2012), $228-229$.

83 Maged El Setouhy et al. "Moral Standards for Research in Developing Countries from "Reasonable Availability" to "Fair Benefits," 22.

${ }^{84}$ Adriana Petryana. When experiments travel: Clinical trials and the global search for human subjects, 19.

${ }^{85}$ Ruth Macklin. Ethics in Global Health: Research, Policy and Practice. 229.

${ }^{86}$ Daniel R. Kuritzkes. "Ethical Conduct of Research in Resource-Limited Settings," The Journal of Infectious Diseases. No. 189(2004):764.

${ }^{87}$ Daniel R. Kuritzkes. Ethical Conduct of Research in Resource-Limited Settings, 765
} 


\section{THE JOURNAL OF HEALTHCARE ETHICS \& ADMINISTRATION}

Vol. 5 | No. 1 (Fall/Winter 2019)

incurred), and justice (the principle of equitable selection of research subjects). The limited resources in developing countries raises special concerns about the exploitation of research subjects; appropriate standards of care; and subsequent availability of treatments proven to be useful by the studies in question. According to Benjamin Caballero, incorporating a proposed principle of a collaborative partnership between investigators and sponsors in developed countries and local researchers, policymakers, and communities in developing countries might resolve many issues. Participation of local collaborators as equal partners helps to ensure that the proposed research is acceptable and relevant to the host country - adding the benefit of helping to build local capacity for research and healthcare delivery; and influence local healthcare policy. ${ }^{88}$

There may be many reasons for corporations from developed countries to promote and fund research in less-developed countries. It could be in response to regulatory demands for local data; to enhance their corporate image within the local scientific community, and cost advantages to performing some of the research and development work. Benjamin Caballero also notes that given their economic power and flexibility, such large corporations may be influential on the current research practices in many lessdeveloped countries. ${ }^{89}$ Social value is required to conduct ethical research; through the generation of knowledge that can lead to improvements in health; otherwise, research exposes participants to risks for no good reason and wastes resources. Certain benchmarks that ensure social value have been identified: 1 . Determine who benefits from the research - delineate the prospective beneficiaries of the study specifying who is included, such as the local community from which research participants will be enrolled, the host country, or people outside the host country. 2. Outline the potential value for each of the prospective beneficiaries of the research. Each potential beneficiary may rank the health problem's importance differently depending on the country. A good example is Malaria. Developing countries with a prevalence of cerebral malaria may need improved infrastructures, as well as vaccines; which may be different in developed countries, where malaria is contained and may only need for research on prophylactic medications for malaria for touristic purposes.

Benjamin Caballero also observes that more than 90 documents from government, nongovernment, and international organizations are available that provide ethical guidelines for human research as noted by the NBAC. Although it is hard to ascertain the amount of input from less-developed countries, most likely these inputs reflect the beliefs and principles prevalent in those countries. According to Caballero, the NBAC points out at least seven principles with considerable consensus: ${ }^{90} 1$ ) The research plan must receive a prior review by an independent ethics review committee. 1) The research plan must receive the previous evaluation by an independent ethics review committee. 2) Safeguards need to be put in place to protect and reduce the risk to research participants.3) Making sure the research involves a reasonable risk-benefit ratio. 4) Adequate plans must be put in place to ensure the care and compensation of participants for injuries directly related to the research. 5) Informed consent must be provided to and obtained from all participants. 6) Equal consideration and care must be provided to all participants. 7) Equitable distribution of the burden and the benefits of the research must be ensured.

For research performed in less-developed countries by scientists from developed countries, another fundamental principle is relevance to the local situation: the study must address a problem of importance for the local population and thus must have the potential to benefit it. The research aimed at developing drugs that will never be available or affordable for people in less-developed countries may not be ethically appropriate. Service to the community is another area of collaboration - this is different from the potential benefit that research may eventually have for the community. It refers to activities by investigators, aimed at providing a direct and immediate benefit to the community, such as "free immunization, screening for endemic diseases, building basic health care facilities, and assisting in the planning of local or regional health interventions," as pointed by Ezekiel J. Emanuel and Christine Grady. ${ }^{91}$ Currently, many investigators from developed countries are already volunteering some form of community service, such as donating their time for healthcare, or utilizing their research infrastructure as a means to support healthcare activities. ${ }^{92}$

To be a reliable and unbiased advocate of the ethical process, an investigator must have a good measure of intellectual independence. In developed countries, the scientific autonomy of the researcher is sustained in part by the fact that a large proportion of the research budget comes from public funds and by their allocation through a peer review system. Public funding for research is limited and unstable in many less-developed countries; this weakens the political standing of scientists in general and may often result in conflicts of interest. Another factor affecting investigators from less-developed countries may be limited training and expertise in the area of research ethics. A few initiatives and have begun targeting ethics training in less-developed countries.

\footnotetext{
${ }^{88}$ Benjamin Caballero. "Ethical issues for collaborative research in developing countries," American journal of Clinical Nutrition, no. 76(2002):718.

${ }^{89}$ Benjamin Caballero. "Ethical issues for collaborative research in developing countries," 717.

90 Benjamin Caballero. "Ethical issues for collaborative research in developing countries," 717-718.

91 Benjamin Caballero. "Ethical issues for collaborative research in developing countries," 718-719.

92 Paul Ndbele. "Research Ethics," in The SAGE Handbook of Healthcare Ethics: Core and Emerging Issues, 234.
} 


\section{THE JOURNAL OF HEALTHCARE ETHICS \& ADMINISTRATION}

Vol. 5 | No. 1 (Fall/Winter 2019)

Practice overwhelms ethics in terms of who controls international guidelines for ethical research and their capacity to protect the rights, interests, and wellbeing of human subjects globally. ${ }^{93}$ Society is becoming more and more sensitive to human abuses; it is universally accepted that it is unethical to exploit vulnerable populations. ${ }^{94}$ Governments throughout the world are taking a more active part in ensuring the ethical conduct of research. With these developments research ethics will continue to grow in its relevance. ${ }^{95}$ Research involving humans subjects cannot be legitimately neglected, therefore permissible when the importance of the objective is tremendous, and risk is small - as long as trial participants entering the trials knowingly wishes to enter the trial, and are not worse off and have a chance of being better off later. ${ }^{96}$

\section{CONCLUSION}

Healthcare cannot be reduced to commodification; it will distort the socio-political commitment that founded the Declaration. ${ }^{97}$ The development of the current international guidelines was dominated by pharmaceutical companies - issues such as the use of placebos, the standard of care, and ancillary care have been protracted. ${ }^{98}$ The number of investigations conducted by multinational laboratories to produce medications to meet the epidemiological needs of poorer countries is proportionately small because of the less financial returns. ${ }^{99}$ In the interest of closing the 10/90 gap and also ensuring that research is recognized as one of the enterprises, it may be useful to avail some community benefits to communities participating in research as a way of ensuring that undue inducement on the individual is avoided. ${ }^{100}$ International research should be guided by universal standards and guidelines that are similar to the ones in the West, modified to accommodate the country's social values and needs.

\section{BIBLIOGRAPHY}

Baum, M Botbol. "The shrinking of human rights: the controversial revision of the Helsinki Declaration", HIV Medicine, 1 (2000): 238-245.

Caballero, Benjamin. "Ethical issues for collaborative research in developing countries", American journal of Clinical Nutrition, 76 (2002): 717-20.

Chadwick, Ruth, Have, Henk ten and Meslin, Eric. The SAGE Handbook of Healthcare Ethics: Core and Emerging Issues. Edited by. Ruth Chadwick, Henk ten Have and Eric Meslin, Los Angeles: SAGE, 201

Centers for Disease Control and Prevention (CDC). "HIV Surveillance Report: Diagnoses of HIV Infection in the United States and Dependent Areas," vol 29 (2017).

Retrieved from: https://www.cdc.gov/hiv/statistics/overview/index.html

Emanuel, Ezekiel J., Grady, Christine, Crouch, Robert A., Lie, Reidar K., Miller, Franklin G., and Wendler, David. The Oxford Textbook of Clinical Research Ethics. Edited by Ezekiel J. Emanuel, Christine Grady, Robert

\footnotetext{
${ }^{93}$ Ezekiel J. Emanuel and Christine Grady. "Four Paradigms of Clinical Research and Research Oversight," in The Oxford Textbook of Clinical Research Ethics, ed. Ezekiel J. Emanuel, Christine Grady, Robert A. Crouch, Reidar K. Lie, Franklin G. Miller and David Wendler, (Oxford/New York: Oxford University Press, 2008), 227.

94 Ezekiel J. Emanuel and Christine Grady, "Four Paradigms of Clinical Research and Research Oversight" in The Oxford Textbook of Clinical Research Ethics, 228.

95 Vilhjalmur Arnason, Hongwen Li and Yali Cong. "Informed Consent" in in The SAGE Handbook of Healthcare Ethics: Core and Emerging Issues, ed. Ruth Chadwick, Henk ten Have and Eric Meslin, (Los Angeles: SAGE, 2011), 112.

96 M Botbol-Baum. "The shrinking of human rights: the controversial revision of the Helsinki Declaration", 244.

97 Volnei Garrafa, "International Research" in The SAGE Handbook of Healthcare Ethics: Core and Emerging Issues, ed. Ruth Chadwick, Henk ten Have and Eric Meslin, (Los Angeles: SAGE, 2011), 344.

98 Paul Ndbele. "Research Ethics," in The SAGE Handbook of Healthcare Ethics: Core and Emerging Issues, 323.

99 Paul Ndbele. "Research Ethics," in The SAGE Handbook of Healthcare Ethics: Core and Emerging Issues, 307-309.

100 Paul Ndbele. "Research Ethics," in The SAGE Handbook of Healthcare Ethics: Core and Emerging Issues, 308.
} 


\section{THE JOURNAL OF HEALTHCARE ETHICS \& ADMINISTRATION}

Vol. 5 | No. 1 (Fall/Winter 2019)

A. Crouch, Reidar K. Lie, Franklin G. Miller and David Wendler, Oxford/New York: Oxford University Press, 2008.

Emanuel, Ezekiel J., Wendler, David, Killen, Jack and Grady, Christine. "What Makes Clinical Research in Developing Countries Ethical? The Benchmarks of Ethical Research", The Journal of Infectious Diseases. 189 (2004): 930-7.

Ekopimo Ibial, et.al. "Ethical considerations in industry sponsored Multiregional Clinical Trials," Pharmaceutical Statistics, 9 (2010): 230-241.

Garrafa, Volnei, Solbakk, Jan Helge, Videl, Susana, Lorenzo, Claudio. "Between the needy and the greedy: the quest for a just and fair ethics of clinical research." Journal of Medical Ethics, 36 (2010), 500-504

Kaiser Family Foundation (KFF). "The Global HIV/AIDS Epidemic," (2019). Retrieved from: https://www.kff.org/global-health-policy/fact-sheet/the-global-hivaids-epidemic/

Kuritzkes, Daniel R. Ethical Conduct of Research in Resource-Limited Settings, The Journal of Infectious Diseases. 2004;(189):764-765.

Lorenzo, Claudio, Garrafa, Volnei, Solbakk, Jan Helge, and Videl, Susana. “Hidden risks associated with clinical trials in developing countries", Journal of Medical Ethics, 36 (2010): 111-115.

Macklin, Ruth. Double standards in medical research in developing countries. Cambridge UK: Cambridge University Press, 2004.

Macklin, Ruth. Ethics in Global Health: Research, Policy and Practice. (New York: Oxford University Press, 2012.

Oliver, Paul. The student's guide to research ethics. Maidenhead, UK: McGraw Hill/Open University Press, 2010.

Petryana, Adriana. When experiments travel. Clinical trials and the global search for human subjects. Princeton and Oxford: Princeton University Press, 2009.

Setouhy, Maged El., et al. "Moral Standards for Research in Developing Countries from "Reasonable Availability" to "Fair Benefits"". The Hastings Center Report, 34, no. 3 (2004), 17-27.

UNAIDS. "Global HIV \& AIDS statistics - 2018 fact sheet." Retrieved from: https://www.unaids.org/en/resources/fact-sheet

Voo, Teck-Chuan, Chin, Jacqueline and Campbell, Alastair V. "Multinational Research", The Hastings Center Bioethics Briefing Book, 107-110.

World Health Organization (WHO). "HIV/AIDS fact sheet." (2019). Retrieved from: https://www.who.int/news-room/fact-sheets/detail/hiv-aids 